\title{
Elaboration and Characterization of Macroporous Bioceramics using Polymeric Sponge Replication Method
}

\author{
Kamel Chaari ${ }^{1, *}$, Jamel Bouaziz ${ }^{1}$, Khaled Bouzouita ${ }^{2}$ \\ ${ }^{1}$ Advanced Materials Laboratory, Department Materials Engineering and Industrial Management, National Engineering \\ School of Sfax (ENIS), University of Sfax, Route Soukra Km 3.5 B.P. 1173, Sfax, 3038, Tunisia \\ ${ }^{2}$ Department Physics and Chemistry, Preparatory Engineering Institute of Monastir (IPEIM), Rue Ibn Eljazzar, Monastir, \\ 5019, Tunisia
}

*Corresponding author: E-mail: kamel.chaari@enis.tn; Tel.: 0021697535218

Web of Science Researcher ID:

ORCID ID: orcid.org/0000-0001-8156-1595

Scopus ID: https://www.scopus.com/authid/detail.uri?authorld=14919070200

DOI: 10.5185/amlett.2020.111578

Biomedical porous fluorapatite scaffolds were fabricated using an improved polymeric sponge replication method. The specific formulations and distinct processing techniques such as the mixture of water and dispersant (Sodium TriPolyPhosphate) as solvent, the multiple coatings with the desired viscosity of the Fap slurries were duplicated from Chaari et al. [11]. The heat treatment was conducted in two stages: a delicate stage of polymeric structure degradation at $290^{\circ} \mathrm{C}$ and then at $600^{\circ} \mathrm{C}$ followed by a sintering stage at $1000^{\circ} \mathrm{C}$ for three hours. The obtained porous Fap scaffolds had uniform porous structures with completely interconnected macropores of $850 \mu \mathrm{m}$. In addition, micropores of $4 \mu \mathrm{m}$ were formed in the skeleton of the scaffold. Finally, the porous Fap scaffold with a porosity of $65 \mathrm{vol} . \%$ and a surface of $400 \mathrm{~mm}^{2}$ had a compressive strength of $7 \mathrm{MPa}$.

\section{Introduction}

The application of calcium phosphate ceramics has become largely used in the biomedical field because of the close similarity of its structure and chemical composition to natural bone. Indeed, Wei and Ma [1] observed that fluoroapatite (Fap) and hydroxyapatite (Hap) were capable of biomineralization, osteoinduction, and osteointegration. Similarly, Liu [2], Tas et. al., [3], Rao, Roopa and Kannan [4] and Smolen et. al., [5] agreed that Fap and Hap presented a good biocompatibility. Equally, Singh [6] praised apatites for their bioactivity. In addition, Ben Ayed, Bouaziz and Bouzouita [7-9], and Ben Ayed and Bouaziz [10] reported that Fap $\left(\mathrm{Ca}_{10}\left(\mathrm{PO}_{4}\right)_{6} \mathrm{~F}_{2}\right.$ : Fap) proved to have similar physicochemical properties to the natural bone. Furthermore, Chaari et. al., $[\mathbf{1 1}]$ and Chaari, Bouaziz and Bouzouita [12] observed that this material showed a good thermal stability. Moreover, Nabiyouni et. al., [13] and Elghazel, Taktak and Bouaziz [14] revealed that Fap had a good resistance corrosion in a physiological medium. Athanaela et. al., [15] and Tredwin et. al., [16], argued that the amount of the Fluoride ions $\mathrm{F}^{-}$ released directly affected the cell attachment and the proliferation, morphology and differentiation of osteoblast cells. Athanaela et. al., [15] explained this by the fact that the fluorine ion itself enhances mineralization and crystallization.
In parallel, Yang and Xiang [17] and Chen et. al., [18] insisted that other properties were required for a biomaterial to be a good replacement for natural bone such as biocompatibility, strength, fatigue durability, non-toxicity, corrosion resistance, and sometimes aesthetics. Within the same line of thought, Zhou and Lee [19] revealed that any clinical applicability of bioceramics was restricted by its poor mechanical strength. Hence, research focused on the porosity as a vital property to enhance the efficiency of a material in this field. Indeed, $\mathrm{Lu}, \mathrm{Lu}$ and Xiao [20], Tampieri et. al., [21], Lu et. al., [22] and Kim et. al., [23] agreed that because bioceramic scaffolds were porous biomaterials, they were perfect materials as a replacement for natural bone.

As a consequence, research revealed that whereas macroporosity with pore diameter greater than $100 \mu \mathrm{m}$ represented a paramount advantage of the structure because it facilitated cells proliferation, microporosity with pore diameter lesser than $10 \mu \mathrm{m}$ allowed the penetration of physiologic liquids in the implant. Hence, Lobo et. al., [24] designed a biphasic calcium phosphate ceramic for bone regeneration. Furthermore, Gauthier et. al., [25], Hing et. al., [26], Hing, Wilson and Buckland [27] Legros et. al., [28] and Mastrogiacomo [29] used porosity as a strategy to control the dissolution and re-precipitation rate since they discovered that a higher porosity rate induced a faster speed of the implant degradation and the natural bone 


\section{Advanced Materials Letters www.vbripress.com/aml}

proliferation. However, despite this consensus on the merit of porosity, there was a major concern with the use of porous implants in highly loaded applications. Indeed, there were observed negative effects of porosity on fatigue strength of the material.

For this reason, the main objective of this work was to attempt to optimize the mechanical strength of the porous bioceramics through the control of their pore size, shape and distribution adopting an improved sponge replication method.

\section{Experimental}

\section{Materials used}

Following the wet method adopted by Ben Ayed et. al., [7] and Chaari et. al., [11], Fap was synthesized according to the following reaction:

$$
\begin{aligned}
6\left(\mathrm{NH}_{4}\right) 2 \mathrm{HPO}_{4} & +10 \mathrm{Ca}\left(\mathrm{NO}_{3}\right)_{2}+2 \mathrm{NH}_{4} \mathrm{~F}+6 \mathrm{NH}_{3(a q)} \\
& \longrightarrow \mathrm{Ca}_{10}\left(\mathrm{PO}_{4}\right)_{6} \mathrm{~F}_{2}+20 \mathrm{NH}_{4} \mathrm{NO}_{3}+6 \mathrm{H}_{2} \mathrm{O}
\end{aligned}
$$

A calcium nitrate solution $\left(\mathrm{Ca}\left(\mathrm{NO}_{3}\right)_{2} \cdot 4 \mathrm{H}_{2} \mathrm{O}\right.$, Merck) was slowly added using a peristaltic pump to a boiling diammonium phosphate $\left(\left(\mathrm{NH}_{4}\right)_{2} \mathrm{HPO}_{4}\right.$, Merck $)$ and ammonium fluoride $\left(\mathrm{NH}_{4} \mathrm{~F}\right.$, Merck) solution containing $\mathrm{NH}_{4} \mathrm{OH}$ to maintain the $\mathrm{pH}$ at 9 . The precipitate was then filtered, washed with hot distilled water, dried at $70^{\circ} \mathrm{C}$ overnight and calcined at $500^{\circ} \mathrm{C}$ for $1 \mathrm{~h}$ under nitrogen atmosphere. The physical and thermal characteristics of this powder are presented in Table 1.

Table 1. Characterization of the Fap powder.

\begin{tabular}{cccccc}
\hline & SSA $^{(1)}$ & D $_{\text {BET }}$ & $\begin{array}{c}\text { DTA } \\
\text { (endothermic peak) }\end{array}$ & $\begin{array}{l}\text { Sintering } \\
\text { domain }^{(2)}\end{array}$ & $\mathbf{d}_{\text {th }}{ }^{(3)}$ \\
\hline Fap & $29 \mathrm{~m}^{2} \cdot \mathrm{g}^{-1}$ & $0,065 \mu \mathrm{m}$ & $1180^{\circ} \mathrm{C}$ & $715-1100^{\circ} \mathrm{C}$ & 3,19 \\
\hline
\end{tabular}

(1) specific area

(2) sintering domain temperature determined by shrinkage

(3) theoretical density

The dispersant used in the suspension preparation, sodium tripolyphosphate $\left(\mathrm{Na}_{5} \mathrm{P}_{3} \mathrm{O}_{10}\right.$ : Stpp), was provided by Alkimia, Tunisia. Three polyurethane foam ranges were used as support and marked: M15-17, M20-22 and M28-30 corresponding respectively to 43.39 and 22 pores per inch. These ranges of foam presented the advantage of having entirely opened and uniform cells. Porosity was often expressed in number of pores per inch (ppi). Therefore, the higher the ppi index was, the smaller the macropore size was.

\section{Porous fap ceramic preparation}

The porous bioceramic were prepared using the impregnation of a macroporous structure in wellproportioned slurry. Before proceeding to the impregnation of samples, it was necessary to undertake studies of the solid-liquid interface characterization and the rheological behavior of concentrated suspensions. The optimum conditions leading to slurries well dispersed, stable and tape casting in the polyurethane foam macroporosities were identified following Chaari et. al., [11]. The optimal conditions were the following: $60 \mathrm{wt} \%$ Fap; $0.7 \mathrm{wt} \%$ Stpp; $\mathrm{pH}$ of the suspension approximately 6.5 providing a viscosity higher than $100 \mathrm{mPa}$.s, using a constant shear rate at $100 \mathrm{~s}^{-1}$.

This work adopted the method that create an identical copy of the sponge where the microporosity and mesoporosity would be filled with the suspension and the macroporosity would be kept as the porosity of the material. Moreover a few macropores were obstructed to improve the mechanical resistance of the obtained bioceramic since biomaterials such as apatite were characterized by low mechanical resistance. The manufacturing method used was inspired by Wang et. al., [30] and Bowen and Thomas [31]. Indeed, the polyurethane foams were impregnated in the optimal slurry. When removed from the slurry, the specimen was a composite of biomaterial and polymer. These polymeric foams with various macroporosity sizes were retrieved full concentrated suspension. The slurry excess was removed with a foam pressing hand. Finally, the samples were sintered at $\mathrm{T}>900{ }^{\circ} \mathrm{C}$ after normal heating under air flue at $\mathrm{T}<500{ }^{\circ} \mathrm{C}$.

The temperature of the polyurethane elimination was evaluated using thermogravimetric analysis with several heating kinetics (Setaram DTA-TG).

Mechanical properties of porous Fap specimens were assessed using compressive strength testing (Lloyd Instruments). The maximal rupture strength was determined using the equation (1)

$$
\sigma_{c}=\frac{F}{s}
$$

where $(F)$ is the tensile strength and $(s)$ is the sample area, perpendicular to the load application axis.

Morphologies and microstructures of the sintered porous samples were observed using a scanning electron microscopy (SEM, Philips XL 30). The pore size distribution and porosity of the samples were analyzed using a mercury intrusion porosimetry (Micromeritics Auto Pore IV 9500). Three to four specimens were selected to determine porosity with an error of less than $1 \%$ of the measured porosity value. The compressive strength of samples was measured using a universal material testing machine (Lloyd testing machine) at a crosshead speed of $1.0 \mathrm{~mm} / \mathrm{min}$.

\section{Results and discussion}

\section{Optimization of the drying and the calcination conditions}

Because the drying might cause cracks in the porous materials with low thickness walls, it was considered a critical stage. As a consequence, this process was given special attention in this work. After drying the samples overnight at room temperature, they were dried in an oven at $100^{\circ} \mathrm{C}$ for $5 \mathrm{~h}$. These conditions appeared sufficient in function of the specimen's size and the slurry water contents.

Then, knowing that the generation of macroporosities required calcinations and sintering, it was necessary to spray the polymeric foam. This process had to be conducted respecting several conditions. Firstly, special care had be 


\section{Advanced Materials Letters www.vbripress.com/aml}

taken so as not to damage the not-yet-sintered structures. Secondly, special attention should be considered so as not to leave any residues after the material calcination. Thirdly, the furnace should not be contaminated by the release of hydrocyanic acid. Therefore, the organic matrix of the samples had to be degraded in a special degassing furnace. The best way to optimize the thermal cycle was to perform thermogravimetric analyzes of the foams with various kinetic heating. Fig. 1(a) Shows the mass loss in function of the temperature rate raising. It was observed that despite the similarity of the mass loss pattern at the three tested rates of 1,3 and $5{ }^{\circ} \mathrm{C} \cdot \mathrm{min}^{-1}$, the temperature raising rate of $1^{\circ} \mathrm{C} \cdot \mathrm{min}^{-1}$ yielded the same mass loss at a temperature $<400^{\circ} \mathrm{C}$. Hence, this latter temperature rate raising was adopted in this study since it served two objectives; namely, the energy saving and the desired gas release speed. Fig. 1(b) illustrates the mass release in function of temperatures. It revealed that over $80 \%$ of the weight loss occurred at temperatures ranging between 270 and $450^{\circ} \mathrm{C}$. This work revealed that temperatures lower than $270^{\circ} \mathrm{C}$ seemed insufficient to trigger the polymer mass loss; i.e. to help gas release. In contrast, temperatures higher than $450^{\circ} \mathrm{C}$ seemed to lead to partial or total burnout of the organic structure. The comparative analysis of the isotherms allowed to choose a temperature close to $290^{\circ} \mathrm{C}$ with a duration of about $16 \mathrm{~h}$. This cycle seemed to allow the elimination of more than $80 \%$ of the polymer mass. Then, the residue was removed during a temperature increase rate of $1^{\circ} \mathrm{C} \cdot \mathrm{min}^{-1}$ up to $600^{\circ} \mathrm{C}$. The resulting specimens reached a critical low mechanical strength but were handled manually.
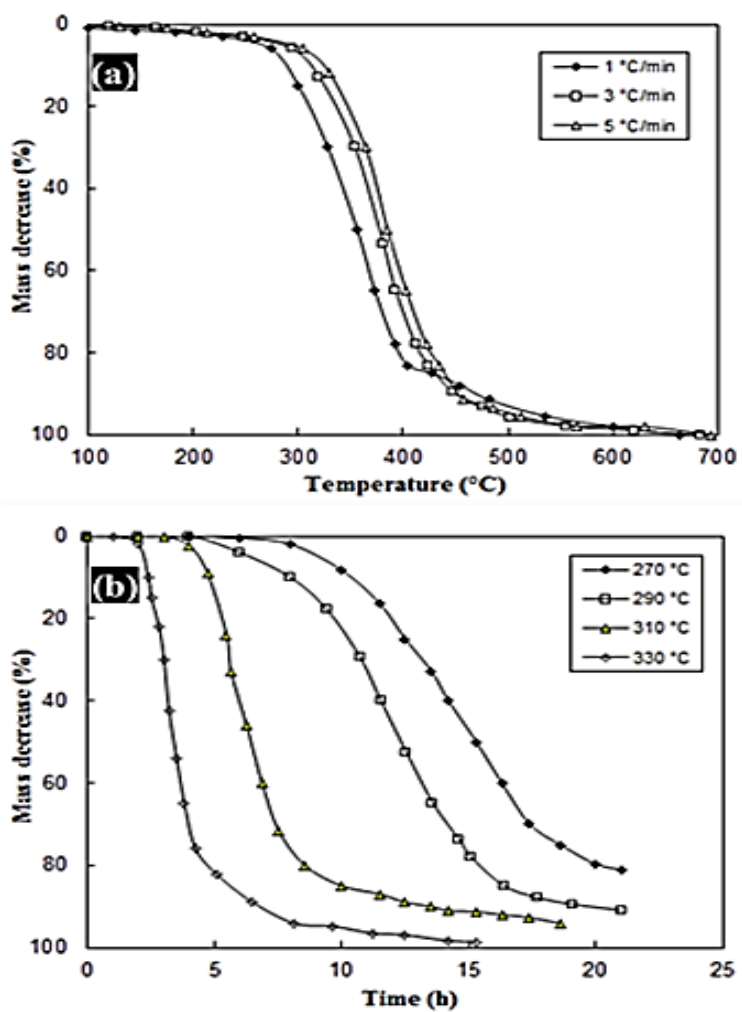

Fig. 1. Thermogravimetric analysis (a) Mass loss in function of temperature raising rate; (b) Mass loss in function of heating temperatures.

\section{Sintering and characterization of macroporous samples}

After the calcination stage, the resulting specimens had a relative density close to $50 \%$ of the theoretical density. The obtained material was formed by weakly linked grains. At cellular body, the material contained two types of porosity: a residual microporosity resulting from granular assembling and a macroporosity created intentionally. The sintering process resulted in the wall densification with partial or total microporosity disappearance and the preservation of the macroporisity.

This study collected all the parameters that affected the mechanical behavior of the bioceramics under investigation. As a result, two types of parameters were highlighted. Firstly, there were the parameters characterizing the samples sintering conditions such as the sintering temperature and the sintering time. Secondly, there were the parameters characterizing the specimen morphology such as the specimen shape and surface and the pore diameter.
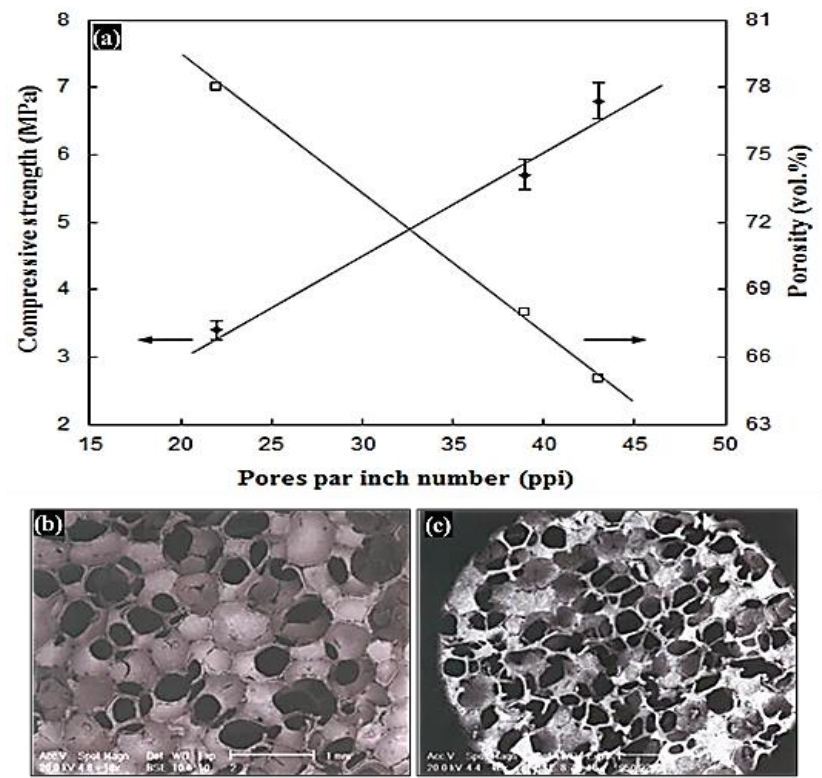

Fig. 2. Graphic presentation and SEM images of the bioceramic macropores compressive strength evolution. (a) Measured porosity and compressive strength in function of ppi; (b) SEM micrograph of sample with $22 \mathrm{ppi}$; (c) SEM micrograph of sample with $43 \mathrm{ppi}$ (scale $1 \mathrm{~mm}, 48 \mathrm{x}$ ). (ppi: pores by inch).

\section{Effect of pore diameter}

Fig. 2 exhibits the graphic presentation and SEM images of the bioceramics compressive strength evolution. As can be clearly seen on the graph, the increase of the macropores diameters resulted in a decrease in the mechanical strength. This finding would confirm the observation mentioned in section 1 above about the critical low mechanical strength of the samples. It can be explained by the fact that although there is an integral transmission of the forces applied gradually in the plans perpendicular to the pressure applied axis, the rupture strength depends on the number of contact points between two cells junctures; i.e. the number of vertical walls surrounding the pores. Consequently, it can be admitted that the number of inter-pore walls would be 


\section{Advanced Materials Letters www.vbripress.com/aml}

responsible for the specimen mechanical resistance. Fig. 2(b) and Fig. 2(c) would add further support to this idea. Indeed, as can be clearly seen in Fig. 2(b), the number of walls between the pores were lower than the number of walls separating the pores in Fig. 2(c) corresponding to the number of ppi in the former polymer. Therefore, the compressive strength of the sample with $22 \mathrm{ppi}$ (3.4 MPa) would be much lower than that in the sample with 43 ppi (6.8 MPa). In other words, the higher the ppi number was, the greater the number of walls was and therefore the stronger it resisted to pressure.

Hence, it can be hypothesized that there were two correlated phenomena: (i) an increase of the number of walls per inch ${ }^{2}$ as a consequence of the increase in ppi; (ii) an increase of the cells blocked number as a consequence of the pore size decreases. This hypothesis may lead to find a compromise between the obstruction of a certain number of pores causing a reduction of porous volume from 78 vol\% for 22 ppi to 64 vol\% for 43 ppi which would enhance the breaking strength. This hypothesis helped to decide that 43 ppi was the optimum choice for a satisfactorily resistant polymeric foam with the adequate pore size for medical use.

\section{Effect of the sintering temperature}

As can be seen in Fig. 3(a), the sintering of samples was conducted in temperatures ranging between $800{ }^{\circ} \mathrm{C}$ and $1250{ }^{\circ} \mathrm{C}$ for $2 \mathrm{~h}$. The compressive strength seemed to have increased with the increase of temperature while its porosity volume decreased.

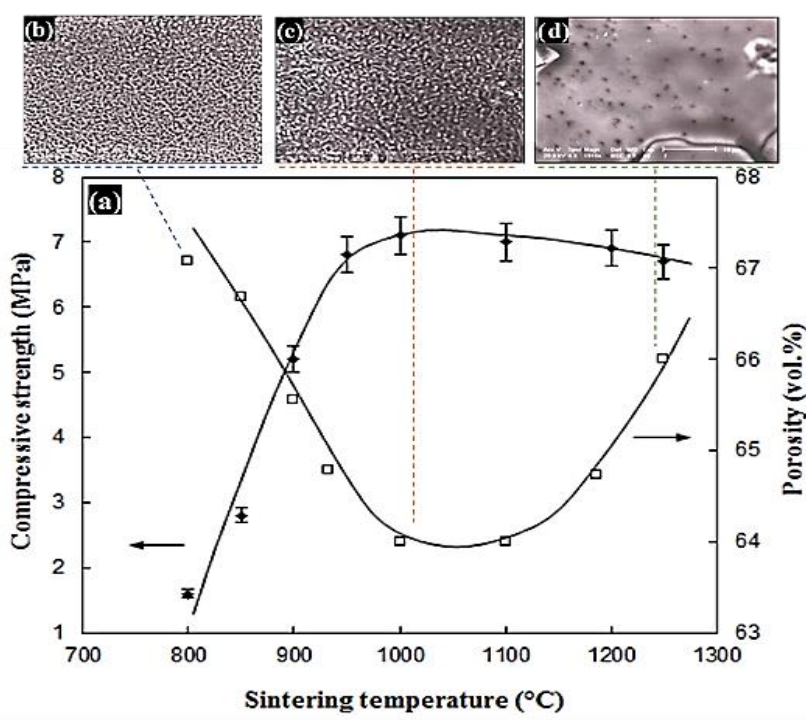

Fig. 3. Graphic presentation and SEM images of the effect of the sintering temperature on the porosity and the compressive strength of bioceramics; (a) Graphic presentation of the effect of the sintering temperature on the porosity and the compressive strength; (b) SEM micrograph of sample solid wall sintered at $800{ }^{\circ} \mathrm{C}$ for $2 \mathrm{~h}$; (c) SEM micrograph of sample solid wall sintered at $1000{ }^{\circ} \mathrm{C}, 2 \mathrm{~h}$; (d) SEM micrograph of sample solid wall sintered at $1250{ }^{\circ} \mathrm{C}, 2 \mathrm{~h}$

The decrease of the pore volume could be explained by an increase in wall densification around the macropores. Fig. 3(b) and Fig. 3(c) illustrate this microstructure evolution. Indeed, in Fig. 3(b), and Fig. 3(c), the SEM microgrphs of the samples sintered at $800{ }^{\circ} \mathrm{C}$ and $1000{ }^{\circ} \mathrm{C}$, respectively, the pore density was clearly very high although it actually decreased from $67 \mathrm{vol} \%$ to $64 \mathrm{vol} \%$ as indicated in Figure 3a. However, porosity substantially decreased at the sintering temperature $1250{ }^{\circ} \mathrm{C}$ as shown in Fig. 3(d). Simultaneously, the compressive strength, which was just above $1 \mathrm{MPa}$ at $800{ }^{\circ} \mathrm{C}$, rose sharply with the increase of temperature to reach $7 \mathrm{MPa}$ at $1000{ }^{\circ} \mathrm{C}$, as shown in Fig. 3(a). Hence, the lowest porosity volume corresponded to the highest compressive strength. This can be explained by the fact that the decrease of the pore volume resulted in a better wall densification surrounding the pores.

The re-increase in the porosity volume at temperatures greater than $1000^{\circ} \mathrm{C}$ and the gradual decrease in the compressive strength would be attributed to the reappearance of micropores. This was rightly explained by Ben Ayed, Bouaziz and Bouzouita [7] and Franz and Telle [32] as a result of the liquid phase formation and the volatile products departure generated by the Fap hydrolysis reaction. At this stage, the excessive presence of micropores can initiate specimens rupture as illustrated by Fig. 3(d).
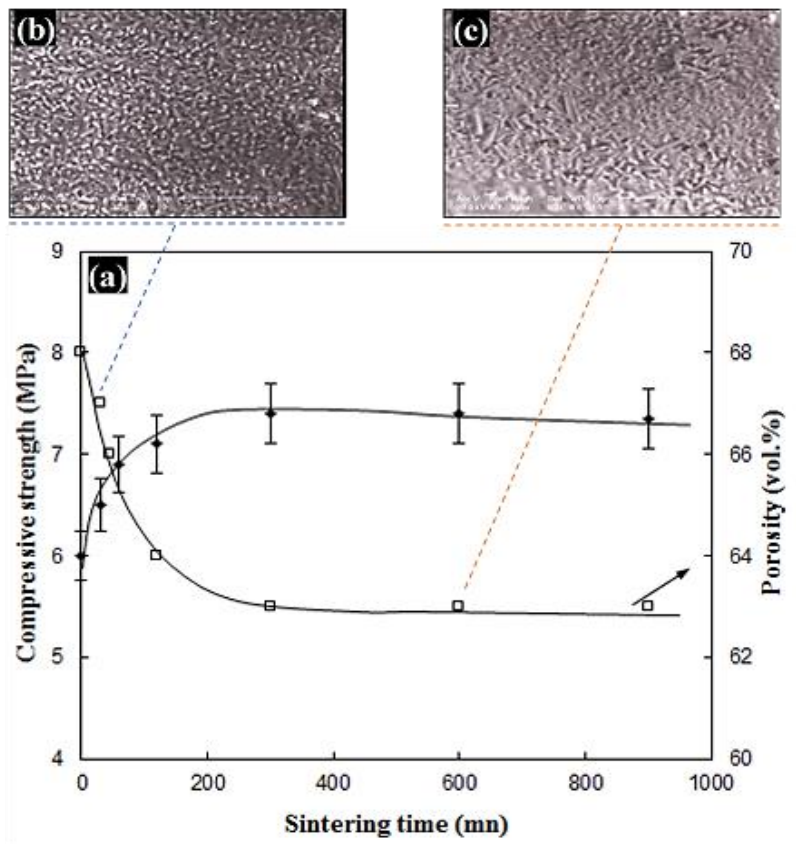

Fig. 4. Effect of sintering time on porosity and compressive strength of the bioceramics: (a) graphic presentation of effect of sintering time on porosity and compressive strength; (b) SEM micrograph of sample solid wall sintered at $1000^{\circ} \mathrm{C}$ for $120 \mathrm{mn}$; (c) SEM micrograph of sample solid wall sintered at $1000{ }^{\circ} \mathrm{C}$ for $600 \mathrm{mn}$.

\section{Effect of the sintering time}

Fig. 4 shows the effect of sintering time on porosity and compressive strength: The graphic presentation exhibited in Fig. 4(a), shows clearly that the compressive strength increased in function of the heating time from $6 \mathrm{MPa}$ to 7.5 MPa. Then, it stabilized after $300 \mathrm{mn}$. In contrast, the porosity volume of the sample decreased in function of the heating time from $67 \mathrm{vol} \%$ to $63 \mathrm{vol} \%$. Then, it stabilized 


\section{Advanced Materials Letters www.vbripress.com/aml}

after the same period of time. This observation was confirmed by the SEM images presented in Fig. 4(b) and Fig. 4(c). Indeed, whereas Fig. 4(b) shows a dense porosity at the beginning of the heat treatment, Fig. 4(c) exhibits a less dense porosity after $300 \mathrm{mn}$ of heat treatment. This can be explained by the fact that during sintering the wall microstructure of the pores was consolidated by two mass transfer mechanisms, i.e., volume diffusion and diffusion at the grain boundaries. Nevertheless, beyond $300 \mathrm{mn}$, the contribution of these mechanisms to the densification increase of the pore walls seemed to have ceased.

\section{Effect of the specimen surface area on the compressive strength}

Fig. 5 exhibits the effect of the surface area on the compressive strength. The compressive strength depends on the number of contact points between two pores, i.e. the number of the vertical walls these two pores. This number of walls being directly proportional to the sample surface, it would be logical to expect that the compression strength increases proportionally with the surface area. However, as can be clearly observed in Fig. 5, the greater the surface area was, the lesser the compressive strength became. Indeed, the compressive strength decreased from 8.1 MPa for an area of $5 \times 5 \mathrm{~mm}^{2}$ to only $5.6 \mathrm{MPa}$ for an area of $25 \times 25 \mathrm{~mm}^{2}$.

To better understand this unexpected relation between the surface area and the compressive strength, it was hypothesized that for the same number of vertical walls per $\mathrm{mm}^{2}$, the difference of the breaking strength values would be attributed only to the non-uniformity of the mechanical behavior of every walls. Indeed, a closer observation of the damaged samples because of their brittleness revealed that they had a heterogynous wall thickness. Precisely, the walls surrounding the pores grew thinner and thinner at the center of the sample where the surface area was larger. Therefore, it would be highly recommended to pay special attention during the impregnation stage of polymeric foams in order to reproduce pore walls with a homogenous thickness.

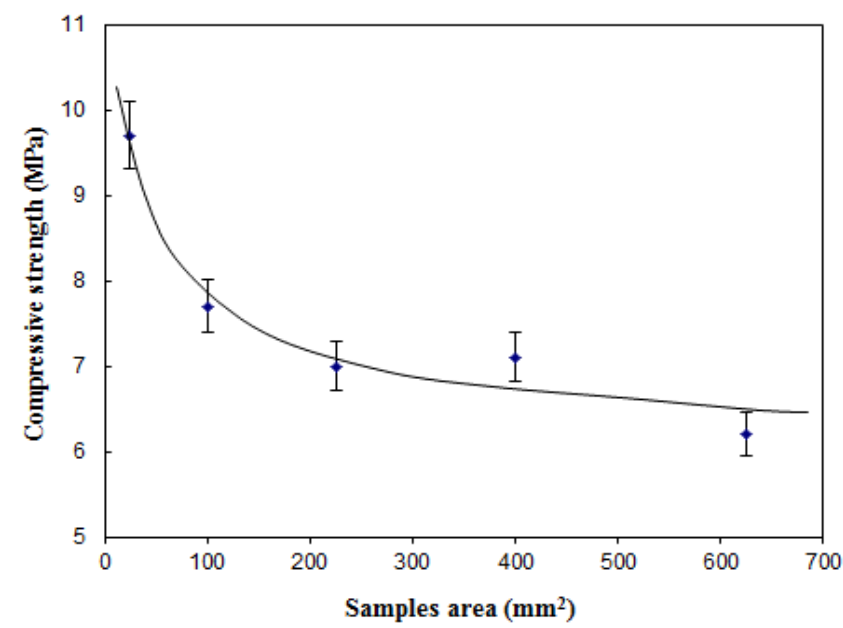

Fig. 5. The compressive strength evolution in function the samples surface area.

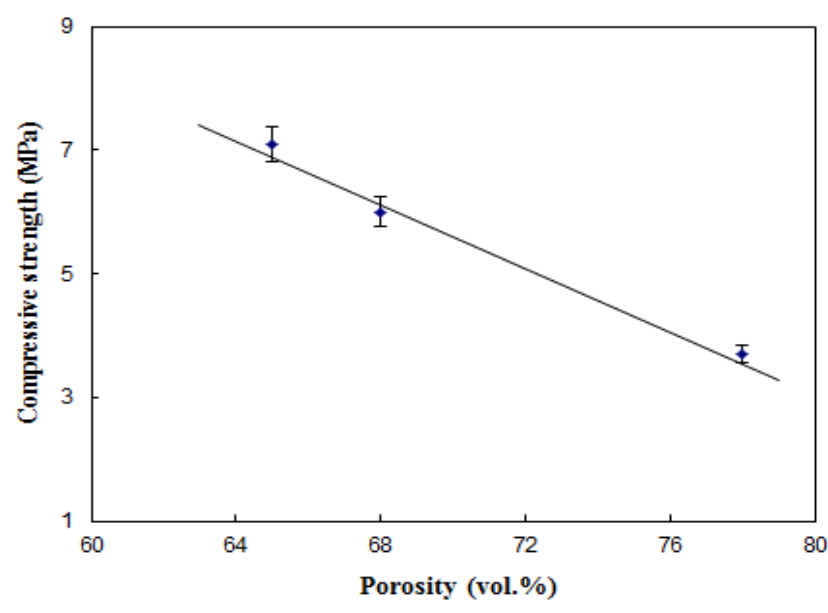

Fig. 6. Evolution of the compressive strength in function of the volume percentage of the pores in bioceramics.

\section{Effect of the porous volume}

As can be seen in Fig. 6, the compressive strength had an indirect relation with the porosity volume percentage. In other words, the increase in porous volume percentage seemed to induce a decrease in the rupture strength. Indeed, for $65 \mathrm{vol} \%$ of porosity, the compressive strength was 7 $\mathrm{MPa}$. However, for while $78 \mathrm{vol} \%$ of porosity, the compressive strength dropped to only $4 \mathrm{MPa}$.

This finding was in total agreement with Chaari et. al., [33] who designed dry process porous bioceramics with a porosity of $48.5 \mathrm{vol} \%$ and a rupture strength of $4 \mathrm{MPa}$. This product had a better compressive strength than that produced by Slosarczyk [34] with a porous volume equal to $64 \mathrm{vol} \%$ and a compressive strength of only $1.89 \mathrm{MPa}$. However, Lelièvre [35] obtained a better compressive strength of $4.2 \mathrm{MPa}$ with a porosity of $48.5 \mathrm{vol} \%$. Neverless, this scholar's finding required optimum conditions that were very difficult to achieve in normal production environments. Similarly, Descamps et. al., [36] reported that they obtained a compressive strength of 18 MPa without offering a plausible explanation for this high value. However, Liu [37], offered an approach to the fracture behavior evolution as a function of pore morphology theorizing that the mechanical strength of Fap having spherical pores can be computed using the equation: $\sigma_{\mathrm{c} \text { sphère }}=1860 \exp \left(-9 \mathrm{v}_{\mathrm{p}}\right)$, where $\mathrm{v}_{\mathrm{p}}$ is a porous volume expressed between 0 and 1 . Applying this equation to Clement and Faber's [38] bioceramic with 65 vol\% spherical pores, this scholar claimed that the obtained compression strength was only $13 \mathrm{MPa}$.

\section{Conclusion}

In conclusion, this work attempted to design an improved biomedical porous Fap using a polymeric sponge replication method. The porous Fap scaffolds with an open and interconnected porous structure were obtained after optimizing the conditions of impregnation and sintering of the products. The as-prepared Fap scaffolds contained 850 $\mu \mathrm{m}$-macropores and $4 \mu \mathrm{m}$-microspores. The optimized 


\section{Advanced Materials Letters www.vbripress.com/aml}

porous Fap scaffold with a porosity of 65 vol\% had a compressive strength of $7 \mathrm{MPa}$. The obtained values were of the same order of magnitude as those reported in literature for the same type of material and would meet the requirements in terms of resistance of human spongy bone. Nevertheless, despite the fact that this mechanical resistance of the porous bioceramics may be below the required resistance of the permanent implant, the real advantage of pores would lie in the fact that they would allow the bone fluid to pass through and form bone in an ultimate phase. The replication structure of bioceramics would be expected to disappear completely. Hence, the mechanical strength of the implanted part would become equal to that of the natural bone. More importantly, further research would be imperative to enhance the compressive strength of bioceramic by integrating other materials that respect the clinical standards such as the biocompatibility and bio-functionality.

\section{Acknowledgement}

The authors would like to express their gratitude to Dr. Ayadi Hajji for his correcting and improving the style and English of the manuscript.

\section{Conflicts of interest}

There are no conflicts to declare.

\section{Keywords}

Biomaterials, macroporous materials, microstructure, mechanical properties.

\section{Received: 05 May 2020}

Revised: 16 May 2020

Accepted: 01 September 2020

\section{References}

1. Wei, G.; Ma, P.X.; Biomaterials, 2004, 25, 4749

2. Liu D.; Ceram. Int., 1997, 23, 135.

3. Tas, C. A.; Korkusuz, F.; Tumucin, M.; Akkas, N.; J. Mater. Sci. Mater. Med., 1997, 8, 91.

4. Rao, R.; Roopa, H. N.; Kannan, T. S.; J. Mater. Sci. Mater. Med., 1997, 8, 511 .

5. Smolen, D.; Chudoba, T.; Malka, I.; Kedzierska, A.; Lojkowski, W.; Swieszkowski, W.; Kurzydlowski, K. J.; Kolodziejczyk, M.; Mierzynska, M.; Lewandowska-Szumiel, M.; Int. J. Nanomedicine, 2013, 8,653 .

6. Singh, A.; Bull. Mater. Sci., 2012, 35, 1031.

7. Ben Ayed, F.; Bouaziz, J.; Bouzouita, K.; J. Eur. Ceram. Soc., 2000, 20, 1069.

8. Ben Ayed, F.; Bouaziz, J.; Bouzouita, K.; J. Alloys Compd., 2001, 322, 238.

9. Ben Ayed, F.; Bouaziz, J.; Bouzouita, K.; Ann. Chim. Sci. Mat., 2006, 31, 393

10. Ben Ayed, F.; Bouaziz, J.; Ceramics Int., 2008, 34, 1885.

11. Chaari, K.; Baklouti, S.; Bouaziz, J.; Bouzouita, K.; Ann. Chim. Sci. Mat., 2004, 29, 1.

12. Chaari, K.; Bouaziz, J.; Bouzouita, K.; J. Colloid Interface Sci., 2005, 285, 469 .

13. Nabiyouni, M.; Zhou, H.; Luchini, T. J. F.; Bhaduri, S. B.; Mater. Sci. Eng. C, 2014, 37, 363.

14. Elghazel, A.; Taktak, R.; Bouaziz, J.; Ceram. Int., 2015, 41, 12340.

15. Athanaela, J.; Mangalarajc, D.; Hongb, S. I.; Masudad, Y.; Rheee, Y. H.; Kime, H. W.; Mater. Chem. Phys., 2013, 137, 967.

16. Tredwin, C. J.; Young, A. M.; Abou Neel, E. A.; Georgiou, G.; Knowles, J. C.; J. Mater. Sci. Mater. Med., 2014, 25, 47.

17. Yang, J.; Xiang, H. J.; J. Biomech., 2007, 40, 2377.
18. Chen, H.; Wang, C.; Zhu, X.; Zhang, K.; Fan, Y.; Zhang, X.; Mater. Sci. Eng. C, 2014, 43, 182.

19. Zhou, H.; Lee, J.; Acta Biomater., 2011, 7, 2769

20. Lu, G.; Lu, G. Q.; Xiao, Z. M.; J. Pulp. Pap. Sci., 1999, 6, 359.

21. Tampieri, A.; Celotti, G.; Sprio, S.; Delcogliano, A.; Franzese, S.; Biomaterials, 2001, 22, 1365.

22. Lu, W. W.; Zhao, F.; Luk, K. D. K.; Yin, Y. J.; Cheung, K. M. C.; Cheng, G. X.; Yao, K. D.; Leong, J. C. Y.; J. Mater. Sci., 2003, 14 , 1039.

23. Kim, S. W.; Jung, H.-D.; Kang, M.-H.; Kim, H.-E.; Koh, Y.-H.; Estrin, Y.; Mater. Sci. Eng. C, 2013, 33, 2808.

24. Lobo, S. E.; Arinzeh, T. L.; Materials, 2010, 3, 815.

25. Gauthier, O.; Bouler, J. M.; Aguado, E.; Legeros, R. Z.; Pilet, P.; Daculsi, G.; J. Mater. Sci. Mater. Med., 1999, 10, 199.

26. Hing, K. A.; Annaz, B.; Saeed, S.; Revell, P. A.; Buckland, T.; $J$. Mater. Sci. Mater. Med., 2005, 16, 467.

27. Hing, K. A.; Wilson, L. F.; Buckland, T.; The Spine J., 2007, 7, 475.

28. Legeros, R. Z.; Lin, S.; Rohanizadeh, R.; Mijares, D.; Legeros, J. P.; J. Mater. Sci. Mater. Med., 2003, 14, 201.

29. Mastrogiacomo, M.; Scaglione, S.; Martinetti, R.; Dol-cini, L.; Beltrame, F.; Cancedda, R.; Quarto, R.; Biomaterials, 2006, 27, 3230.

30. Wang, C.; Chen, H.; Zhu, X.; Xiao, Z.; Zhang, K.; Xingdong Zhang, $\mathrm{X}$; Materials Science and Engineering C, 2017, 70, 1192.

31. Bowen, C. R.; Thomas, T.; Ceramics International, 2015, 41, 12178

32. Franz, E. D.; Telle, R.; Reaction hot pressing fluorapatite for dental implants; In Hight Tech Ceramics; P. Vincenzini (Ed); Elsevier Sci. Pub. B.V, Amesterdam, NLD, 1987.

33. Chaari, K.; Ben Ayed, F.; Bouaziz, J.; Bouzouita, K.; Materials Chemistry and Physics, 2009, 113, 219.

34. Slosarczyk, A.; Powd. Met. Inter., 1989, 4, 21.

35. Lelièvre F., Etude du coulage et du frittage de 1'hydroxyapatite, application à la réalisation de pièces cellulaires, Thèse de l’Université de Limoges, 1992.

36. Descamps, M.; Richart, O.; Hardouin, P.; Hornez, J. C.; Leriche, A.; Ceramics International, 2008, 34, 1131.

37. Liu, D.; Jour. Mat. Sci. Letters, 1996, 15, 419.

38. Clément, D.; Faber, J. (Eds); Actualités en Biomatériaux ; Romillat, FRA, 1992

\section{Graphical abstract}

Overview diagram of porous bioceramic elaboration by wet process. From Polyurethane foam for resistant bioceramic foam.

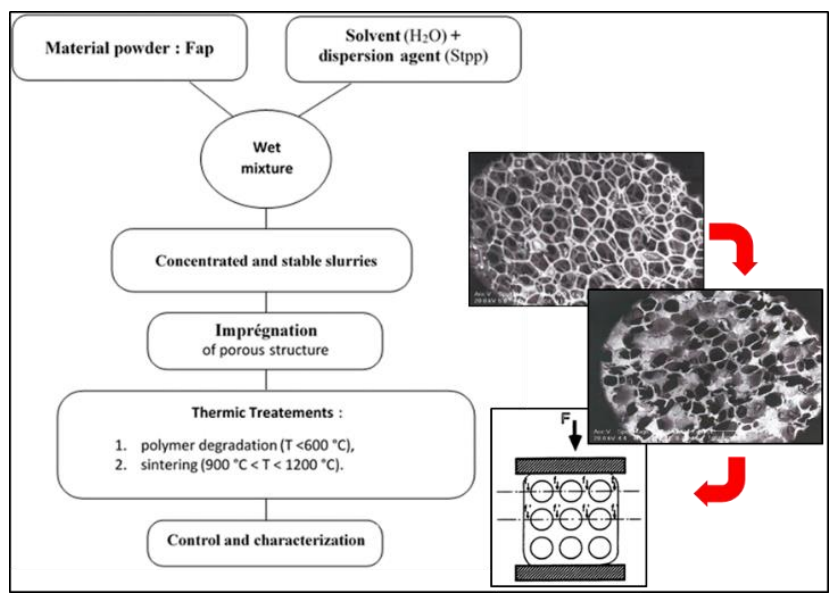

